\title{
The Impact of HRIS on HRM Effectiveness: A Study in Large Scale Group of Company in Sri Lanka
}

\author{
Sulochana, KAB and Sajeewanie, TL
}

\begin{abstract}
Area of the Study

Most of the organizations have used technology in the form of Human Resource Information System (HRIS), Electronic Human Resource Management System (e-HRM system) etc. in managing their human resources in order to improve HRM effectiveness. However a deficiency of researches in this study area in Sri Lanka can be observed. Therefore this research study is aimed to examine the impact of HRIS on HRM effectiveness in a large scale group of company in Sri Lanka.
\end{abstract}

\section{Problem of the Study}

The main focus of this research study is to identify and examine the impact of HRIS on HRM effectiveness in Sri Lankan context. Hence the research problem of the study is what is the impact of HRIS on HRM effectiveness in selected large scale group of company in Sri Lanka?

\section{Method of the Study}

The selected population was all the Strategic Business Units (SBUs) in the selected large scale group of company which are nearly twenty subsidiaries and the population has considered as a whole for the study without considering a particular sample. The primary technique of data collection was a descriptive questionnaire which was distributed between HR personnel and Non- HR personnel in the company including CEOs of SBUs, $H R$ representatives and IT representatives. Data was analyzed using univariate analysis, correlation and regression analysis with the SPSS (16.0 version).

\section{Findings of the Study}

According to the findings at the end of the study there is a weak positive relationship between the impact of HRIS and HRM effectiveness in the selected group of company. Further it was found that the Impact of HRIS has the possibility to account for $10.0 \%$ of the variation in HRM effectiveness. However when considering the responses of HR personnel only, $28.2 \%$ of the variance of the HRM effectiveness is explained by the Impact of HRIS and according to Non HR personnel, only $6.3 \%$ of the variance of the HRM effectiveness is explained by the impact of HRIS.

\section{Conclusion of the Study}

It is concluded that there is a weak positive relationship between the impact of HRIS and HRM effectiveness in selected large scale company. If the utilization of HRIS is increased further, it could be used for achieving more favorable results in enhancing HRM effectiveness in the company.

Keywords: HRIS, HRM Effectiveness, Technology, HR Personal, Non HR Personal 


\section{Introduction}

Numerous organizations in developed countries now are highly reliant on their human capital for their competitive advantage (Lawler, Levenson \& Boudreau 2004). According to Alwis (2010, p. 47), "people are the key asset that is capable of growth and development". Therefore people have to be managed in a way they perform beyond many administrative and legally mandated tasks, by being more of a business and strategic partner. Even though the role of human resource (HR) in organizational success and sustained competitive advantage has been widely acknowledged, there is great degree of contention on how effective HR management (HRM) function is in any organization (Yusoff 2001).

Wright et al.'s (2001) measure of HRM effectiveness was adapted which focuses on HR's effectiveness in performing various roles and HR's effectiveness of its contributions. The effectiveness of HR roles are apprehended the essence of the roles suggested by Ulrich (1997). HRM effectiveness is the value of what HR practitioners do for the organization and how HRM practices are linked to organizational outcomes (Huselid 1995; Boxall, 1996; Baron \& Kreps 1999; Wright at el. 2001, as cited in Ruel, Bondarouk \& Velde 2007). According to Gibson (2006), since the effectiveness is the degree to which carefully established goals are met; HRM effectiveness obviously means the degree to which it is executing its various roles and the degree to which it is meeting the needs of its clients. As Pratheepan and Arulrajah (2012) state the perceived quality of services provided by the integrated HR system plays a significant role in the perceived effectiveness of the HR system.

As Kavanagh, Thite and Johnson (2012) state the effective management of human resources in a firm to gain competitive advantage requires timely and accurate information on current and potential employees in the labour market and that requirement can be greatly contented with the evolution of computer technology. Therefore there is a rising interest in moving towards technology based HRM practices from traditional methods (Guest 1990, as cited in Tansley, Newell \& Williams 2001). Since the beginning of the 1990s, organizations have familiarized with web-based applications for HRM purposes by transforming traditional HRM into a web-based/electronic HRM (web-based HRM or e-HRM) (Hempel 2004). The distinction between e-HRM and Human Resource Information System (HRIS) is that a HRIS tends to be limited and affects only those individuals working in or with the organization's HR function. In addition, HRIS is an older concept, pre-dating the emergence of networking and internet-based communications technology. In contrast, e-HRM represents an internetbased information technology that reaches all employees, at all levels within an organization (Ruël, Bondarouk \& Looise 2004). Thus, this study has considered HRIS to be a part of eHRM to the extent it includes internet-based information technology; however, e-HRM is a broader construct in that it is not limited to individuals or processes attached to the HR function within an organization.

Today HRIS plays a significant role in contemporary businesses where it helps to achieve many strategic advantages. HRIS can smooth strategic value generation by assisting design and implement internally consistent policies and practices that safeguard human assets contribute achieving business objectives (Farndale et al. 2010, as cited in Troshani, Jerram \& 
Hill 2011). Organizations are becoming contingent on HRIS to upsurge the effectiveness of HRM (Ball 2001; Lippert and Swiercz 2005, as cited Troshani, Jerram \& Hill 2011). Functionally the HRIS is a software or online solution for the data entry, data tracking, and data information needs of the Human Resources, payroll management and accounting functions within a business (Mukherjee, Bhattacharyya \& Bera 2014). Almost all the HR applications involve the automating of HRM activities (Ngai \& Wat 2006).

In examining the benefits of HRIS there are two extremes, the pure administrative use of HRIS and its strategic use (Tarawneh \& Tarawneh 2011). Eventually the goal of both is to increase organizational value. Administrative HRIS is used in day-to-day operations and it is usually in the form of records that hold employee information. Administrative HR is much more efficient when it is used with IT because HR professionals are better able to handle large amounts of information efficiently. In contrast, strategic HRIS is much more difficult to explain and measure because there is no way to be sure that the benefits are a direct result of strategic deployment of an HRIS system. Strategic HRIS consists of tools that assist in decision making. Mayfield and Lunce (2003) states a noteworthy problem with determining whether HRIS benefits the organization is that of assessing the effect of HR and more predominantly HRIS on the bottom line. There are limited clear cut methods to measure the value of HRIS. While there are measurements for administrative HRIS such as cost reductions in HR departments, it is hard to measure specifically the return on investment and definite improvements in productivity within the HR departments.

\section{Problem Background and the Problem of the Study}

According to Wickramasinghe (2010) in the context of globalization of business operations and interlocking supply chains, research on web-based HRM and HRIS in Sri Lanka is interesting, relevant and timely since there is an increasing interest in understanding technological influence on management, workers and on organization as a whole in nonwestern cultures. According to studies by Alwis (2010), out of his sample of 30 companies with more than 1000 employees situated around Colombo city, $70 \%$ of Sri Lankan companies are rapidly moving towards adopting technology in managing Human Resources but it will take a few more years to move towards complete incorporation of e-HR strategy into the business model. Thus, according to the citations of previous research data, the internet and communication technology have come to the interface of HR practices in Sri Lankan organizations and a significant impact of HRIS and e-HRM on HR practices can be observed mostly in banking sector and manufacturing organizations in Sri Lanka. However, literature has highlighted the slowness of the HRM functions in utilizing IT in comparison with other organizational functions (Cerveny et. al.1993 cited in Wickramasinghe 2010). Hence this research study examines: What is the impact of HRIS on HRM effectiveness in large scale company which can be recognized as a group of company in Sri Lanka?

\section{Research Framework}

All through this research, the impact of HRIS over HRM effectiveness is measured and analyzed. According to Kanthawong (2002) and Hendrickson (2003) past research have suggested that web- based HRM modules like e-HRM, HRIS etc. can increase the efficiency 
and effectiveness of HR activities, improve HR service delivery and transform the role of the HR function into one that is more strategic. Hence HRIS seems to matter for Human Resource Management in the current digital economy. As competitive pressures for many organizations increase, the reliance on the strategic use of IT in HRM to manage the workforce is gaining increasing popularity (Teo, Soon \& Fedric 2007). Further they revealed that the adoption of HRIS in the organization is correlated with impacts such as simplifying work processes in the HR department, improving effectiveness of the HR department, lowering the administrative headcount in the HR department and quicker hiring. Ruël, Bondarouk and Looise (2004) stressed that according to the earlier studies companies progressively more implement HRIS but according to new observations HRM professionals (and their companies) are not surprised anymore by the HRIS phenomenon; instead they have reached a "grown up" stage. However companies start with HRIS because of foreseen advantages that are anticipated to result in a more effective HRM (Bondarouk \& Ruël 2009).

In relation to the previous literature, it could be stressed that there is a notable relationship between HRIS and HRM effectiveness in the organizations. Hence in order to align with this research study the Impact of HRIS can be recognized as the independent variable and on the other hand HRM effectiveness obviously becomes the dependent variable and the hypothesis is developed depending on these two main variables accordingly.

\section{Hypothesis Development}

As Johnston and Carrico (1988) state HRIS is actively used to support the corporate strategy although the competitive potential of HRIS is not considered when defining and developing strategies. There appears to be a shift towards applications which are more strategic, probably because organizations realize that the HRIS can be used for more effective purposes rather than just administrative functions (Teo, Soon \& Fedric 2007). According to Maatman's (2006) analysis of data, collected in the Dutch Ministry of Internal Affairs and Kingdom relations, showed that positive actual use of Emplaza (their web-based HRM module), got along with more positive perceptions of HR effectiveness. Therefore the main hypothesis of this research study is developed considering the impact of HRIS on HRM.

$\mathrm{H}_{1}$ : HRIS has a positive impact on HRM effectiveness in the selected group of company.

In relation to the hypothesis of this study, Figure 1 illustrates the expanded relationship between the Impact of HRIS and HRM effectiveness in selected large scale group company.

\section{Research Method}

This study was conducted in a quantitative design by collecting data through a questionnaire and the two variables were identified and tested based on the hypothesis developed. Since this study focuses on hypothesis testing and identifying correlation between variables, it usually explains the nature of certain relationships and explains the variance in the dependent variable. 
Figure 1:- Conceptual Framework

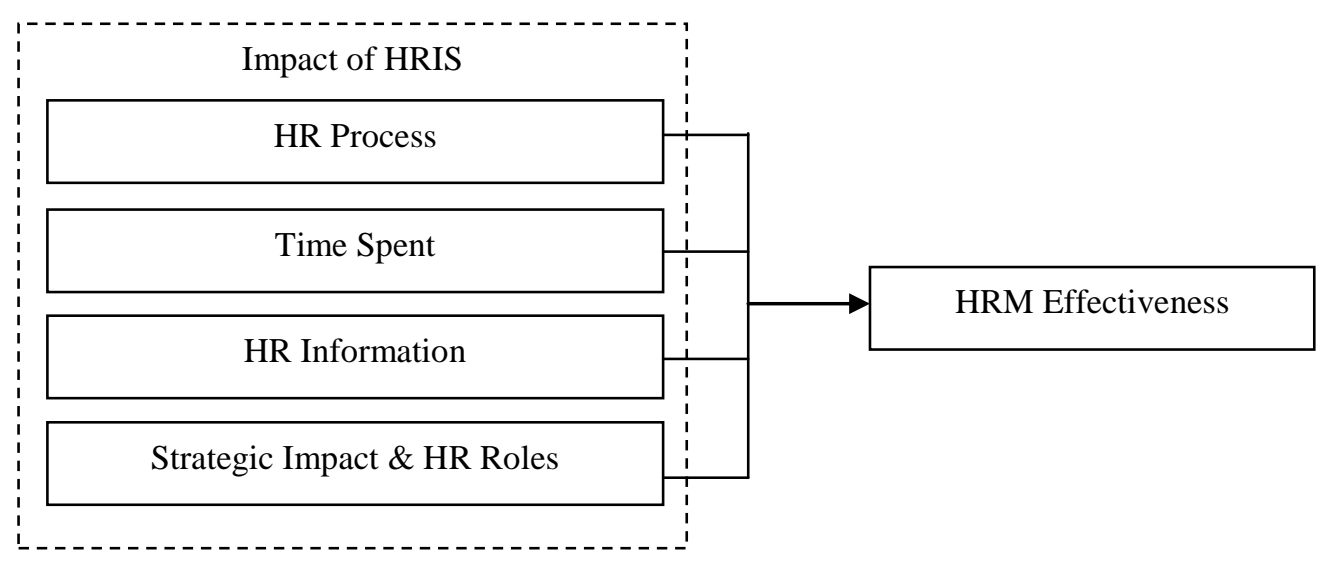

\section{Measures}

A questionnaire was selected as the major source of data collection and the researcher gathered first hand data by distributing the questionnaire. It was considered to be the best method to conduct the survey as the considering sample is busy and there are working in different subsidiaries in different locations across the country of the particular Group of Company. As mentioned earlier the questionnaire was distributed among the HR Personnel (19), non-HR professional-IT (11) and non-HR professional-CEO (06) in the selected Group of company. From all the variables, the demographic variables, i.e. Department, Age, Gender and Designation were analyzed at first. In this study 19 respondents were HR Personnel representing the percentage of 52.8\% and from the rest of 17 Non HR Personnel, 12 respondents were from IT Departments and 5 respondents were CEOs. Out of the $19 \mathrm{HR}$ Personnel respondents, 7 respondents were HR Executives (36.8\%) and other respondents were from each other two categories of Head of the Department (31.6\%) and Assistant Manager (31.6\%) equally. Among the respondents of Non HR Personnel, 9 were IT Executives (52.9\%), 1 was an Assistant Manager of IT (5.9\%), 2 were Heads of IT Divisions $(11.8 \%)$ and rest were CEOs (29.4\%). Apart from that, out of HR respondents, 11 were male representing the percentage of $57.9 \%$ and 8 were female representing $42.1 \%$. From the respondents group of Non HR Personnel 14 were male representing $82.4 \%$ and only 3 were female representing $17.6 \%$. In addition most of the respondents from both HR and Non HR categories were in the age group of 20-30 years. The next highest percentage represented the age group of 31-40 years.

This study used questions which were adapted from already developed standard questionnaires (impact of HRIS-Targowski and Deshpande (2001) and Beadles, Lowery and John (2005) and HRM effectiveness- Maatman (2006) integrating few work of Lepak et al. (2004), Venkatesh et al. (2003) and Sanders and Van der Ven (2004)). All questions were presented as statements and the respondents were supposed to rank them according to a scale. Data was gathered through five point Likert scales which were positive as "Strongly Agree, Agree, Neither Agree nor Disagree, Disagree, Strongly Disagree”. 


\section{Reliability}

The inter item consistency reliability was examined with Cronbach's Alpha test (Kottawatta 2014). The results of Cronbach's alpha test are given in Table 1 which suggests that the internal reliability of each instrument was satisfactory. The content validity of the instrument was made sure by the conceptualization of the variable on the literature and indirect by the high internal consistency reliability denoted Alpha (Kottawatta 2014) and the construct validity of the variables of the study was made sure by the fact that the correlation and regression analysis support the hypotheses formulated linking the relationship between the independent and dependent variables (Kottawatta 2014).

Table 1: Cronbach's Alpha Coefficients

\begin{tabular}{|l|l|c|c|}
\hline \multirow{2}{*}{} & \multirow{2}{*}{ Instrument } & \multicolumn{2}{|c|}{ Cronbach's Alpha } \\
\cline { 3 - 4 } & & HR Respondents & Non HR Respondents \\
\hline 1 & Impact of HRIS & 0.959 & 0.841 \\
\hline 2 & HRM Effectiveness & 0.964 & 0.924 \\
\hline
\end{tabular}

\section{Techniques of Data Analysis}

The researcher conducted a preliminary analysis on descriptive statistics to test the reliability of the data gathered through the pilot test. Data were analyzed using univariate analysis, correlation and regression analysis with the SPSS (16.0 Version).

\section{Results}

Based on the respondents' data, following descriptive statistics can be presented for each variable of the study. The mean value, median, standard deviation, minimum and maximum values are presented in Table 2.

Table 2: Statistics of the distribution of the independent variable: The Impact of HRIS and the dependent variable: HRM Effectiveness

\begin{tabular}{|l|r|r|r|r|}
\hline & \multicolumn{2}{|c|}{ The Impact of HRIS } & \multicolumn{2}{c|}{ HRM Effectiveness } \\
\hline & \multicolumn{1}{|c|}{$\begin{array}{c}\text { HR } \\
\text { Personnel }\end{array}$} & $\begin{array}{c}\text { Non HR } \\
\text { Personnel }\end{array}$ & \multicolumn{1}{c|}{$\begin{array}{c}\text { HR } \\
\text { Personnel }\end{array}$} & $\begin{array}{c}\text { Non HR } \\
\text { Personnel }\end{array}$ \\
\hline Valid & 19 & 17 & 19 & 17 \\
\hline Mean & 3.6786 & 4.1191 & 3.9292 & 3.8046 \\
\hline Median & 3.5644 & 4.0764 & 4.0714 & 3.8333 \\
\hline Std. Deviation & 0.57792 & 0.24199 & 0.69430 & 0.39148 \\
\hline Variance & .334 & .059 & 0.482 & 0.153 \\
\hline Minimum & 2.57 & 3.65 & 2.89 & 3.35 \\
\hline Maximum & 4.42 & 4.51 & 4.80 & 4.70 \\
\hline
\end{tabular}

As indicated by Table 2, the mean value of the distribution of the impact of HRIS of HR personnel is 3.6786 and the mean value of the distribution of Non HR personnel is 4.1191. Hence the impact of HRIS according to the respondents of both categories is "Positive". In contrast, the mean value of the distribution of HRM effectiveness of HR personnel is 3.9292 
and the mean value of the distribution of non HR personnel is 3.8046. Hence HRM effectiveness according to the respondents of both categories is "Good".

The bivariate analysis, Pearson's Correlation between the impact of HRIS and HRM effectiveness of HR and non HR respondents in the selected group of company are illustrated in Table 3.

Table 3: Correlation between the Impact of HRIS and HRM Effectiveness

\begin{tabular}{|l|c|c|c|}
\hline & HR Personnel & Non HR Personnel & All Respondents \\
\hline Pearson Correlation & $0.567^{*}$ & $0.060^{*}$ & $0.355^{*}$ \\
\hline Sig. (1-tailed) & 0.011 & 0.042 & 0.034 \\
\hline
\end{tabular}

* Correlation is significant at the 0.05 level (1-tailed).

According to the results of the pearson's correlation shown in Table 3, there is a positive significance between the Impact of HRIS and HRM effectiveness according to the HR personnel. Pearson correlation between the two variables, when considering HR personnel only is 0.567 , which is positive. Pearson correlation between the two variables regarding non HR personnel is 0.060 , which is positive but relatively a lower value. Yet Pearson correlation between the two variables regarding all the respondents is 0.355 , which is also positive significantly.Thus there are statistical evidences to claim that the impact of HRIS and HRM effectiveness are positively related in selected large scale group of company.

The results of simple regression analysis of the independent variable (the Impact of HRIS) against the dependent variable (HRM Effectiveness) are given in Table 4.

Table 4: Results of Regression Analysis

\begin{tabular}{|l|l|l|l|}
\hline \multirow{2}{*}{ Variables } & \multicolumn{3}{|c|}{ Impact of HRIS } \\
\cline { 2 - 4 } & $\begin{array}{l}\text { HR } \\
\text { Personnel }\end{array}$ & $\begin{array}{l}\text { Non HR } \\
\text { Personnel }\end{array}$ & All \\
\hline Method & Linear & Linear & Linear \\
\hline R Square & 0.322 & 0.004 & 0.126 \\
\hline Adjusted R Square & 0.282 & 0.063 & 0.100 \\
\hline F & 8.059 & 0.053 & 4.904 \\
\hline Significance & 0.011 & 0.042 & 0.034 \\
\hline B- constant & 1.423 & 4.201 & 2.299 \\
\hline b- value & 0.567 & 0.060 & 0.355 \\
\hline
\end{tabular}

As presented in the table 4, according to the respondents as a whole, the gradient (b value) of the regression, is 0.355 , which is significant at $5 \%$ (significance $=0.034$ ). As indicated by $\mathrm{R}$ Squared, $10.0 \%$ of the variance of the HRM effectiveness is explained by the impact of HRIS with the standardized beta of 0.126 . The $\mathrm{F}$ value is 4.904 , which is significant at $5 \%$ (significance $=0.034$ ), which suggests that the impact of HRIS has significantly explained $10.0 \%$ of the variance of the HRM effectiveness. 
This impact can be further explained in accordance with the perceptions of HR and non HR personnel separately. According to the HR respondents, the gradient of the regression, is 0.567 , which is significant at $5 \%$ (significance $=0.011$ ) and $28.2 \%$ of the variance of the HRM effectiveness is explained by the impact of HRIS with the standardized beta of 0.322 . On the contrary, according to the non HR personnel, the gradient of the regression is 0.060 and only $6.3 \%$ of the variance of the HRM effectiveness is explained by the impact of HRIS with the standardized beta of 0.004 .

The hypothesis testing was carried using the results of Pearson's Product Movement Correlation analysis and the results of Regression analysis. According to the results, the correlation coefficient is 0.355 , which is significant at $5 \%(\mathrm{p}=0.034)$. As per the result of simple regression analysis between the two variables the regression coefficient (b) is 0.355 , which is significant at $5 \%$ ( $\mathrm{Sig}$. $\mathrm{T}=0.034$ ). Therefore, according to the results of both tests, the Null hypothesis is rejected and the alternative hypothesis is accepted. Hence the data support the hypothesis that, "HRIS has a positive impact on HRM effectiveness in the selected large scale group of company."

\section{Discussion and Conclusion}

The problem of the study was what is the impact of HRIS on HRM effectiveness in the selected large scale group of company which can be recognized as a group of company in Sri Lanka? According to all the previous analyses, the first specific objective to examine the impact of HRIS on HRM effectiveness in the selected large scale group of company in Sri Lanka was accomplished. Accordingly, there is a weak positive relationship between the Impact of HRIS on HRM effectiveness in the selected large scale group of company. The overall correlation between these two variables was 0.355 which was significant at 0.034 level. According to the results of simple regression analysis, the impact of HRIS found to be positive on HRM effectiveness with the strength of overall $b$ value of 0.355 . Hence, the impact of HRIS can be identified as a predictor of HRM effectiveness of the selected large scale group of company. However, when considering the strength of the $\mathrm{b}$ value of $\mathrm{HR}$ Personnel solely, it was 0.567 , but as per the Non HR personnel it took a lower value of 0.060 representing a very weak impact.

Discussing the level of the impact of HRIS according to the respondents as a whole (HR Personnel and Non HR Personnel), it was found that there is a favourable level of impact of HRIS with the mean value of 3.6786 (according to the HR Personnel) and 4.1191 (according to the Non HR Personnel) and standard deviation of 0.57792 and 0.24199 respectively. As a result it was found that, there is an impact of HRIS on HRM and its effectiveness in the selected large scale group of company.

The findings of this research study empirically endorse the suggestions of various past researchers. As Kanthawong (2002) and Hendrickson (2003) have suggested that web- based HRM modules like e-HRM, HRIS etc. can increase the efficiency and effectiveness of HR activities, improve HR service delivery and transform the role of the HR function into one that is more strategic. The same notion was given by Teo, Soon \&Fedric (2007) stating that 
the adoption of HRIS in the organization is correlated with impacts such as simplifying work processes in the HR department, improving effectiveness of the HR department, lowering the administrative headcount in the HR department and quicker hiring. Correspondingly this study reveals that there is a positive impact of HRIS on HRM effectiveness when considering a Sri Lankan multi business entity; the selected large scale group of company.

Once the second specific objective to observe the advantages and disadvantages of utilizing HRIS in the selected large scale group of company is considered, it was observed that most of the advantages of utilizing HRIS were towards the administrative tasks and some of traditional activities such as,

i. improving the data inputting and data maintaining process while reducing the costs and time

ii. improving the quality of information gathered and improving the communication process

iii. improving the recruitment process

iv. improving the attendance management process

v. improving the payroll and welfare management processes etc.

In contrast, their HRIS was under- utilized compared to the costs and time investments they have made for it and not taking full advantage of the capabilities.According to many respondents,

i. They have not integrated major HR functions such as Training \& Development, Performance Evaluation etc. which could be easily performed using HRIS

ii. Still the HR staff is focusing more on performing administrative and traditional tasks only, deprived of moving forward for strategic activities.

iii. Still the paperwork is relatively high.

Thus, even though there is a positive impact of HRIS on HRM effectiveness in the selected large scale group of company. and even though they have consumed a significant amount of investment for HRIS, it is under- utilized when looking at the data gathered.

\section{Recommendations}

Along with the findings of the research it was possible for the independent variable, i.e. the impact of HRIS to account for $10.0 \%$ of the variation in HRM effectiveness in the selected large scale group of company. while their HRIS is not utilized properly at least to perform major HR functions. However if the utilization of HRIS is increased further, it could be used for achieving more favourable results in enhancing HRM effectiveness in the company. On the other hand superior outcomes can be gained if the HRIS is merged and integrated with other functional systems as it would be supportive in faster decision making and communication purposes in the organization. Later HRIS should exceed its traditional roles in moving towards more strategic directions in order to gain competitive advantages. 


\section{References}

i. Alwis, DC 2010, 'The Impact of Electronic Human Resource Management on the Role of Human Resource Managers', Ekonomika a Management, vol.4, pp. 47-60.

ii. Ball, K 2001, 'The use of human resource information system: A survey', Personal Review, Vol. 30, pp. 677-93.

iii. Baron, J. N., \& Kreps, D. M. (1999). Strategic human resources. Framework for general managers. New York: Wiley and sons.

iv. Beadles, N, Lowery, CM \& John, K 2005, 'The impact of human resource information system: An exploratory study in the public sector', Communication of the IIMA, Vol. 5, No. 4, pp. 39-46.

v. Bondarouk, T \& Ruel, H 2009, 'Electronic Human Resource management: Challenges in theDigital Era,' International Journal of Human Resource Management, vol. 20, No. 3, pp. 503-514.

vi. Boxall, P. (1996) The strategic HRM debate and the resource-based view of the firm. Human Resource Management Journal, 6: 59-75.

vii. Farndale, E., Hugh, S., \& Paul, S. (2010). The role of the corporate HR function in global talent management. Journal of World Business, 45(2), 161-168. http://dx.doi.org/10.1016/j.jwb.2009.09.012

viii. Gibson, CL 2006, 'PHR Exam Prep: Professional in Human Resources', viewed 19 September. http://www.pearsonitcertification.com/store/phr-exam-prep-professionalin-human-

resources9780789734501?w_ptgrevartcl=phr+exam+prep:+strategic+hr+management 438039

9780789734501?w_ptgrevartcl=phr+exam+prep:+strategic + hr+management 438039

ix. Hempel, PS 2004, 'Preparing the HR Profession for Technology and Information Work,' Human Resource Management, vol. 43, pp. 163-177.

x. Hendrickson, AR 2003, 'Human Resource Information systems: Backbone technologyof contemporary Human Resources', Journal of Labor Research, vol. 24, No. 3, pp. 381-394.

xi. Huselid, M. A. (1995), The impact of human resource management practices on turnover, productivity and corporate financial performancell, Academy of Management Journal, Vol.38, No.3, pp. 635-672.

xii. Johnston, HR \& Carrico, SR 1988, 'Developing capabilities to use information strategically', MIS Quarterly, vol. 12, No.1, pp. 37-50.

xiii. Kanthawongs, P 2002, 'Does HRIS Matter for HRM Today?'

xiv. Kavanagh, MJ, Thite, M \& Jonsons, RD 2012, Human Resource Information Systems- Basics, Applications and Future Directions, Sage Publications, United States.

xv. Kottawatta, H 2014, Research guide book, Department of Human Resource Management, Colombo.

xvi. Lawler, EE, Levenson, A, \& Boudreau, JW 2004, 'HR Metrics and Analytics: Use andImpact,' Human Resource Planning, Vol. 27, pp. 27-35. 
xvii. Maatman, M 2006, 'Measuring the effectiveness of e-HRM: The development of an analytical framework for the measurement of e- HRM and its application within a Dutch Ministry'.

xviii. $\quad$ Mayfield, J, Mayfield, M \& Lunce S. 2003, 'Human Resource Information Systems: A Review and Model Development', Advances in Competitiveness Research, vol. 11, no. 1 , pp. 139-151.

xix. Mukherjee, AN, Bhattacharyya, S \& Bera, R 2014, 'Role of Information Technology in Human Resource Management of SME: A Study on the use of Applicant Tracking System', IBMRD's Journal of Management and Research, vol.3, no.1, pp. 1-22.

xx. Ngai, EWT \& Wat, FKT 2006, 'Human resource information systems: a review and empirical analysis', Personal Review, vol. 35, no. 3, pp.297-314.

xxi. Pratheepan, S \& Arulrajah, AA 2012, 'Application of Electronic Human Resource Management (E-HRM) Practices and its Effectiveness in Selected Private Banks in Sri Lanka: An Exploration', Paper presented at the 7th International Research Conference on Management and Finance.

xxii. Ruël, HJM, Bondarouk, TV \& Looise, JK 2004, 'E-HRM: Innovation or irritation; Anexplorative empirical study in five large companies on web-based HRM', Management Revue, vol. 15, No. 3, pp. 364-380

xxiii. Ruel, HJM, Bondarouk, TV \& Velde, MV 2007, 'The Contribution of e-HRM to HRM effectiveness: Results from a quantitative study in a Dutch Ministry', Employee Relations, vol. 29, no. 3, pp. 280-290.

xxiv. Tansley, C \& Watson, T 2000, 'Strategic Exchange in the Development of Human Resource Information Systems (HRIS),' New Technology, Work and Employment, vol.15, no. 2, pp. 108-122.

xxv. Tansley, C, Newell, S \& Williams, H 2001, 'Effecting HRM-style practices through an integrated human resource information system; An e-Greenfield Site?', Personal Review, Vol. 30, No. 3, pp. 351-370.

xxvi. Tansley, C., Newell, S. and Williams, H. (2001). 'Effecting HRM-style practices through an integrated human resource information system'. Personnel Review, 30: 3, 351-370.

xxvii. Tarawneh, MA \& Tarawneh, H 2011, 'The Effect of Applying Human Resources Information System in Corporate Performance in the Banking Sector in Jordanian Firms', Intelligent Information Management, vol. 4, pp. 32-38.

xxviii. Targowski, A. S. and Deshpande, S. P. "The Utility and Selection of an HRIS," Advances in Competitiveness Research, Vol. 9, No. 1, 2001, pp. 42-56.

xxix. Targowski, AS \& Deshpande, SP 2001, 'The utility and selection of an HRIS', Advances in Competitive Research, Vol. 9, No. 1, pp. 42-56.

xxx. Teo, SHTL, Soon, GL \& Fedric, SA 2007, 'The adoption and diffusion of human resources information systems in Singapore' Human Resources, vol. 45, pp. 44-62.

xxxi. Troshani, I., Jerram, C., and Hill, S. R. (2011). Exploring the public sector adoption of HRIS. Industrial Management \& Data Systems, 111(3), 470-488.

xxxii. Ulrich, D 1997, 'HR of the future: conclusions and observations', Human Resource Management, vol. 36 no. 1, pp. 175-9. 
xxxiii. Wickramasinghe, V 2010, 'Employee perceptions towards web-based human resource management systems in Sri Lanka', The International Journal of Human Resource Management, vol. 21, no.10, pp. 1617-1630.

xxxiv. Wright, PM, McMaham, GC, Snell SA, \& Gerthert, B 2001, 'Comparing line and HR executives' perceptions of HR effectiveness: services, roles, and contributions', Human Resource Management, vol. 40, no. 2, pp. 111-123.

xxxv. Yusoff, YM, Abdullah, HS \& Ramayah, T 2009, 'HR Roles Effectiveness and HR Contributions Effectiveness: Comparing Evidence from HR and Line Managers', International Journal of Business Management, vol. 4, No 2,

\section{Sulochana, KAB}

Management Trainee-HR, Winterqiults (Pvt) Ltd

lochana.buddhi@gmail.com

Sajeewanie, TL

Senior Lecturer, Department of Human Resource Management, University of Sri Jayewardenepura

tilasanthi@gmail.com 